\title{
The influence of measles vaccination on the incidence of otosclerosis in Germany
}

\author{
Wolfgang Arnold • Raymonde Busch • \\ Andreas Arnold • Björn Ritscher • Albrecht Neiss • \\ Hans Peter Niedermeyer
}

Received: 4 December 2006 / Accepted: 19 December 2006 / Published online: 13 February 2007

(C) Springer-Verlag 2007

\begin{abstract}
The pathologic process of otosclerosis is characterized by an inflammatory lytic phase followed by an abnormal bone remodeling at very specific sites of predilection. There is a clear genetic predisposition with about half of all cases occurring in families with more than one affected member. Females are affected more frequently than males with an approximate 2:1 ratio. $\mathrm{N}, \mathrm{H}$, and $\mathrm{F}$ measles proteins as well as measles virus RNA have been demonstrated in osteoblasts, chondroblasts, and macrophages of the inflammatory phase of the disease. These observations merely show an association between measles viruses and otosclerosis. In the present study, we tried to prove that there is a causal relationship: voluntary measles vaccination has been available in Germany since 1974. In the absence of official data, we reconstructed the rate of vaccination coverage between 1974 and 2004 using information from the Robert Koch Institute (RKI,
\end{abstract}

W. Arnold $(\bowtie) \cdot$ B. Ritscher $\cdot$ H. P. Niedermeyer Department of Otorhinolaryngology,

Head and Neck Surgery,

Klinikum rechts der Isar,

Technical University of Munich,

Ismaninger Straße 23, 81675 Munich, Germany

e-mail:w.arnold@lrz.tum.de

A. Arnold

Department of Otorhinolaryngology,

Head and Neck Surgery, Inselspital,

University of Bern, Bern, Switzerland

R. Busch · A. Neiss

Institute of Medical Statistics and Epidemiology,

Klinikum rechts der Isar,

Technical University of Munich,

Munich, Germany
Berlin) and from the literature. From the German Federal Office of Statistics, we received the data of 64,112 patients who had been hospitalized between 1993 and 2004 and in whom otosclerosis (ICD-9: 387; ICD-10: H80) had been confirmed. We calculated the effect of measles vaccination on the incidence of hospital treatments for otosclerosis in the period from 1993 to 2004 in Germany. For this purpose, we divided the female and male otosclerosis patients treated as inpatients each year in the observation period into two age groups: those up to 25 years, who had in most cases been vaccinated (designated below as "vaccinated patients") and those over 25 years who mostly could not have been vaccinated (designated below as "unvaccinated patients"). We calculated the incidence of otosclerosis requiring inpatient treatment for the two age groups in each year in the period of observation. For external validation of the study results, the same analysis was carried out in all patients who received inpatient treatment for otitis media in the same period. Between 1993 and 2004 the incidence of hospital treatments for otosclerosis decreased to a significantly greater extent in the vaccinated patients than in the unvaccinated patients. The decline is much greater in men than in women. A comparable effect cannot be demonstrated in patients with otitis media. The results indicate that measles vaccination in Germany has resulted in a significant reduction in the number of hospital treatments for otosclerosis in the vaccinated age groups. We conclude that there is a causal relationship between measles viruses and the development of otosclerosis.

Keywords Otosclerosis $\cdot$ Incidence $\cdot$ Measles virus · Vaccination $\cdot$ Sex differences 


\section{Introduction}

Otosclerosis is a disorder of the bony labyrinth, which is one of the major causes of hearing loss in Caucasians. It only affects human beings. Although the clinical course of progressive conductive, mixed or sensorineural hearing loss associated with otosclerosis is well documented, its etiology remains unknown. The disease is usually transmitted as an autosomal-dominant trait with incomplete $(40 \%)$ penetrance. The degree of penetrance is related to the distribution of the otosclerotic lesions in the otic capsule. Some lesions are located where they cannot cause hearing loss $[1,2]$. About $8 \%$ of male and $12 \%$ of female temporal bones from Caucasians show histological findings of otosclerosis. However, only $10 \%$ of them develop clinical symptoms of mainly conductive or mixed hearing loss when the lesion involves the stapes, representing up to $1 \%$ of the white population $[3,4]$.The black population has fewer cases of otosclerosis, with only $1 \%$ of temporal bones showing histological findings of the disease $[5,6]$.

The age at which hearing loss becomes apparent is variable due to the insidious progression of hearing loss. However, in many cases hearing loss begins in the patient's late teens $[1,6]$. About half of the clinical otosclerosis cases report a family history of this condition. Although genetic, vascular, infectious, and hormonal factors have been suggested as the underlying mechanism of otosclerosis, this hearing disorder is usually considered to be an inherited disease. So far, five genetic loci have been mapped, although none has been cloned [7-10].

In the white population, $90 \%$ of the otosclerotic lesions are located in the area of the oval window causing mainly conductive hearing loss by fixation of the stapes [3-5]. Clinically, females are affected twice as often as males $[11,12]$. The conductive component of hearing loss in otosclerosis can be successfully eliminated by removing the fixed stapes and insertion of a stapes prosthesis. In Germany, this operation is performed during hospitalization for 2-3 days. From various industrial countries, there are reports of a continuous decline in the number of stapes operations, which makes it difficult to teach this delicate surgical procedure in certain areas $[13,14]$. In Denmark, the total number of stapes operations has shown a sustained decrease of $32 \%$ during the last two decades (P. Bretlau, Copenhagen, personal communication). Moreover, a striking shift to older patient groups has been noted and young patients suffering from otosclerosis are becoming rare [15].

During the last 20 years, various research groups have described an association between measles virus infection and the inflammatory process in otosclerosis: in the lytic (inflammatory) phase of otosclerosis (otospongiosis), immunoglobulins are deposited on osteocytes and chondroblasts; a distribution of $80 \% \mathrm{~T}$ lymphocytes and $20 \%$ B lymphocytes indicates the presence of a viral infection $[16,17]$. Using immunohistochemical methods, $\mathrm{N}, \mathrm{H}$, and $\mathrm{F}$ proteins from measles virus have been proven in the cytoplasm of chondroblasts, osteoblasts, and macrophages [18, 19]. Measles virus RNA has been extracted from otosclerotic bone tissue using measles virus-RT-PCR [20-23]. Recently, we performed genotyping of measles virus obtained from bioptic material of six patients (born before 1965, operated in 2000). The phylogenetic analysis resulted in a measles virus genotype $\mathrm{A}$, which was only present in Middle Europe during 1960s. This result indicates a measles virus persistence within the otosclerotic process (submitted for publication). It is assumed that the persistent MV infection occurs in susceptible individuals, leading to inflammation and altered bone metabolism in certain genetically determined areas of the otic capsule. The hypothesis of a genetic tissue alteration and exposure to an infectious agent as prerequisites for development of the disease would more cogently explain incomplete penetrance of a dominant gene $[13,18]$.

Vaccination for measles in Germany was commenced in 1974 on a voluntary basis although the initial application of vaccination was very slow. Nevertheless, immunization resulted in a remarkable fall in the annual incidence of measles. Since an animal model for otosclerosis does not exist and to fullfill Koch's postulate (e.g., the isolation of persistent measles viruses from the infected tissue) is not possible one method to analyze the causal role of measles viruses in otosclerosis is to look for a temporal relationship between immunization and the decline in surgical cases. Theoretically, the effect would be detected clinically when the subjects reached the age typical for manifestation of otosclerotic hearing loss. For example, children immunized in 1970s would reach the age of onset of clinical symptoms in 1990s. Thus, the number of clinical cases would be expected to have decreased in 1990s [13].

\section{Methods}

Since individual information to test the correlation between measles virus vaccination and the incidence of otosclerosis was not available, we used accumulated data. Since 1993, the diagnoses of all persons receiving inpatient treatment in Germany based on the 
International Classification of Diseases (ICD) as well as their age and gender have been reported to the Federal Office of Statistics (Wiesbaden). From there, we received the data of 64,112 inpatients in whom otosclerosis (ICD-9: 387, ICD-10: H80) had been confirmed between 1993 and 2004. These comprised 40,219 women and 23,893 men; the ratio of women to men was 1.68:1. The diagnosis of otosclerosis is unequivocally defined clinically and inpatient treatment for otosclerosis is exclusively for stapes surgery to improve hearing. As described above, only the data from otosclerosis inpatients was available. There was no information available on persons receiving outpatient treatment for otosclerosis. We assumed that the ratio of inpatient to outpatient treatment and also the notification practices over the period of observation (1993-2004) were constant, so that a possible effect of measles vaccination on the incidence of otoslerosis cases treated as inpatients can be generally regarded as an indicator for the effect of vaccination on the development of otosclerosis.

We obtained data from the Robert Koch Institute (RKI, Berlin) or from the relevant literature on the approximate rate of measles vaccination between 1974 and 2004 in Germany. On this basis, the rates of vaccination between 1974 and 2004 were reconstructed. Vaccine manufacturers or pharmacist associations were unable to provide any data on the annual quantity of vaccine sold from which a more precise rate of vaccination could have been calculated for the period between 1974 and 2004 [24-34].

For each year in the observation period from 1993 to 2004, we divided the otosclerosis inpatients (all patients together and divided into women and men) into two age groups: those up to 25 years old who had largely been vaccinated (designated below as "vaccinated patients") and those over 25 years old who mostly would have remained unvaccinated (designated below as "unvaccinated patients"). On the basis of the age and the sex distribution of the population in Germany from 1993 to 2004, we calculated the incidence of otosclerosis requiring inpatient treatment for the two age groups in each year of the observation period from the corresponding frequencies [35]. To appraise the precision of the estimation of the incidence, the $95 \%$ confidence interval was calculated in accordance with the method of Clopper and Pearson [36]. Instead of the frequencies provided by the Federal Office of Statistics, incidences were calculated in order to take into consideration the development of population in the observation period.

If measles vaccination inhibits the development of otosclerosis, the incidences of otosclerosis in the vaccinated patients would have to be lower than in the unvaccinated patients over the period of observation (internal validation). In order to rule out the possibility that an effect attributed to the measles vaccination has a different cause in reality, the data from a bacterial ear infection were accessed (external validation). The Federal Office of Statistics provided us with the data from all persons treated in hospital for otitis media (ICD-9: 382, ICD-10: H66, $n=342,766$ ) in the period from 1993 to 2004 . These comprised 161,661 women and 181,105 men. The ratio of women to men was 1:1.2. This data was processed in the same way as the otoslerosis data (division into vaccinated and unvaccinated patients and calculation of the incidence). A possible difference in the incidences as in the two age groups of the otosclerosis patients is not likely to be manifested in the patients with otitis media, since we assume that the measles vaccinations does not have any effect on the occurrence of a bacterial otitis media. However, if a difference in the incidence is likewise found in this group of patients, it would be evidence against a correlation between measles vaccination and the occurrence of otosclerosis and thus, against an involvement of measles viruses in the development of otosclerosis. The statistical comparison of frequencies and of incidences was made by comparing the corresponding confidence intervals. A difference was considered to be significant when $P<0.05$. The test was two-sided.

\section{Results}

Measles vaccination in Germany started in 1974. According to the literature and data from the RKI (Berlin) the reconstructed vaccination rate in 1980 was about $30 \%$ and reached $65 \%$ in 1982 . From then the vaccination rate with some interruptions slowly increased up to $80 \%$ in 1995 . Between 1995 and 2004 the vaccination rate continuously increased up to $90 \%$ (with regional differences). The average rate of vaccination between 1974 and 2004 was $72 \%$ (Fig. 1).

The frequency and incidence of vaccinated and unvaccinated inpatients suffering from otosclerosis between 1993 and 2004 are listed in Table 1. As well from frequency as from incidence it is obvious that the decline is significantly greater in the vaccinated ( 25 years old or younger) than in the unvaccinated (older than 25 years) patient group.

Between 1993 and 2004 the incidence of hospital treatments for otosclerosis has decreased by $42 \%$ in the vaccinated patients and by $16 \%$ in the unvaccinated patients (Fig. 2). Considering the changes of incidence separately in men and women the incidence of hospital treatments for otosclerosis has decreased by $27 \%$ in the vaccinated women and by $15 \%$ in the unvaccinated 


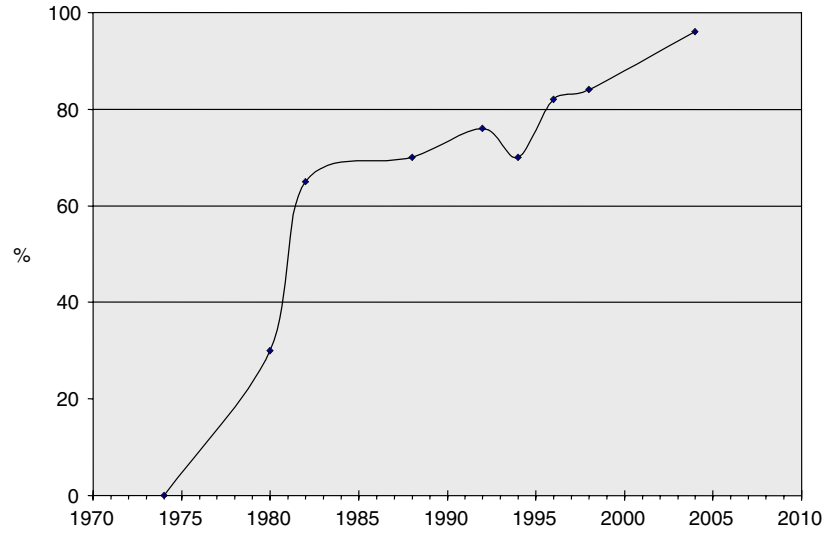

Fig. 1 Measles vaccination in Germany: calculated vaccination rates between 1974 and 2004 according to to data from the Robert Koch Institute and the literature (24-34). The average rate of vaccination is $72 \%$

women. In the men with otosclerosis, the decrease in the incidence of hospital treatment in vaccinated patients was $59 \%$ as compared to $22 \%$ in unvaccinated patients (Fig. 3). It is notable that the incidence of hospital treatments decreased in the observation period not only in the vaccinated, but also in the unvaccinated otosclerosis patients, a phenomenon, which is known as secular trend. However, the decrease in incidence in the vaccinated patients is significantly greater than in the unvaccinated patients. This applies both to women and men as well as to all patients together.

The frequency and incidence of vaccinated $(\leq 25$ years old) and unvaccinated ( $>25$ years old) inpa- tients suffering from otitis media between 1993 and 2004 are listed in Table 2. The incidence of inpatient treatment for otitis media decreased by $14 \%$ in the vaccinated patients but by $17 \%$ in the unvaccinated patients between 1993 and 2004 (women: 10\% as compared to $12 \%$; men: $16 \%$ as compared to $23 \%$ ). There is also a general decrease in the incidence of otitis media patients (secular trend), but this is even greater in the unvaccinated group than in the group of patients vaccinated against measles (Fig. 4).

\section{Discussion}

Investigations on preserved or fresh otosclerosis material in recent years have revealed measles virus-specific proteins and ribonucleic acids in the cytoplasm of chondrocytes, osteoblasts, osteoclasts, and macrophages. Reference material from healthy temporal bones or from other ear diseases than otosclerosis did not contain measles virus proteins or measles virus RNA [16, 18, 19, 21, 37, 38]. Despite the close correlation between bone disease and demonstration of measles infection in cells from the inflammation focus, it is difficult to understand why the measles virus in the unequivocally genetically fixed disease should play a causal role.

Isolation of measles virus from otosclerotic tissue (Koch's postulate) is not possible. There is no animal model for this disease that occurs exclusively in the

Table 1 Frequency and incidence of inpatient treatments for otosclerosis in Germany from 1993-2004

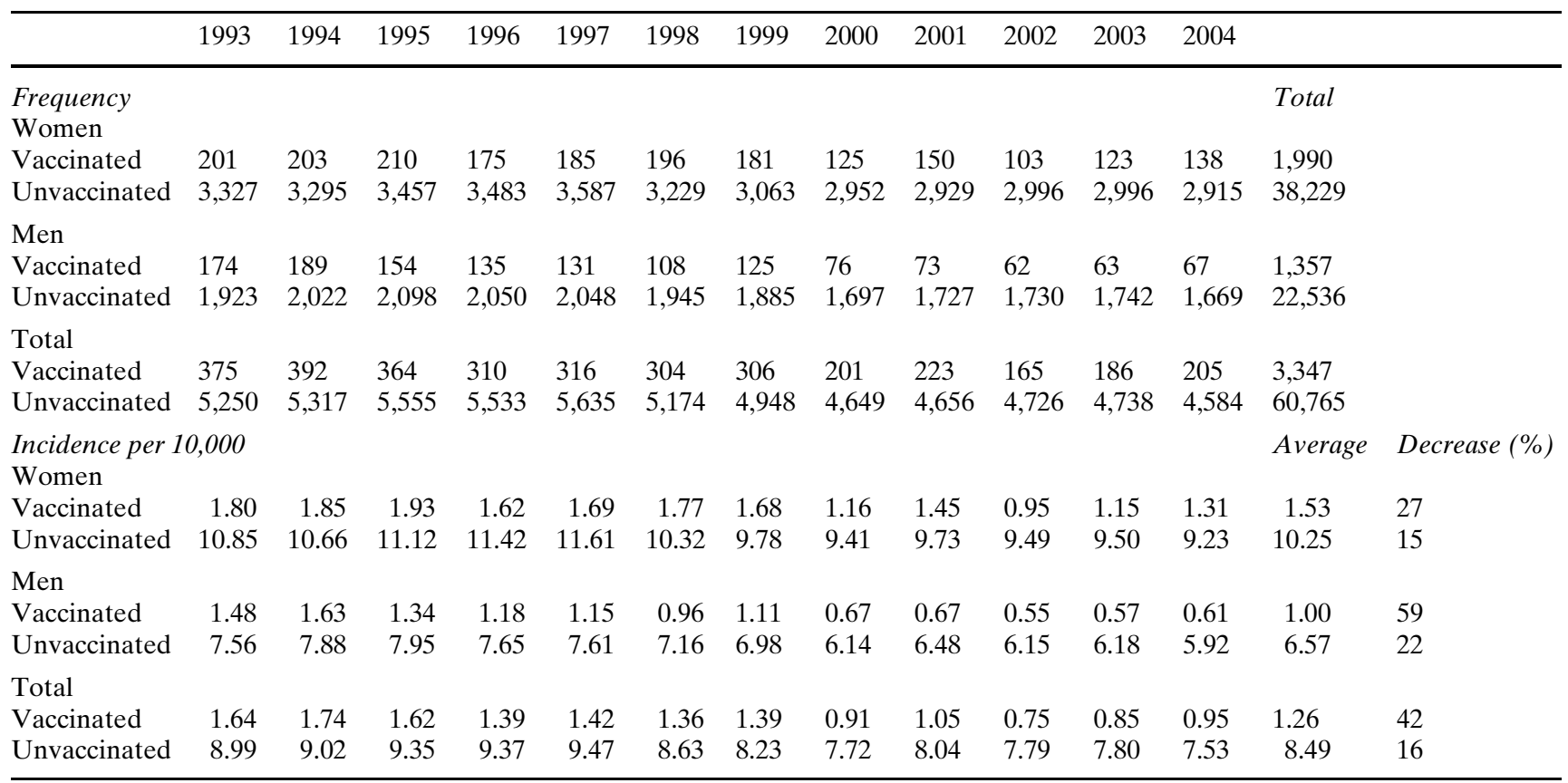




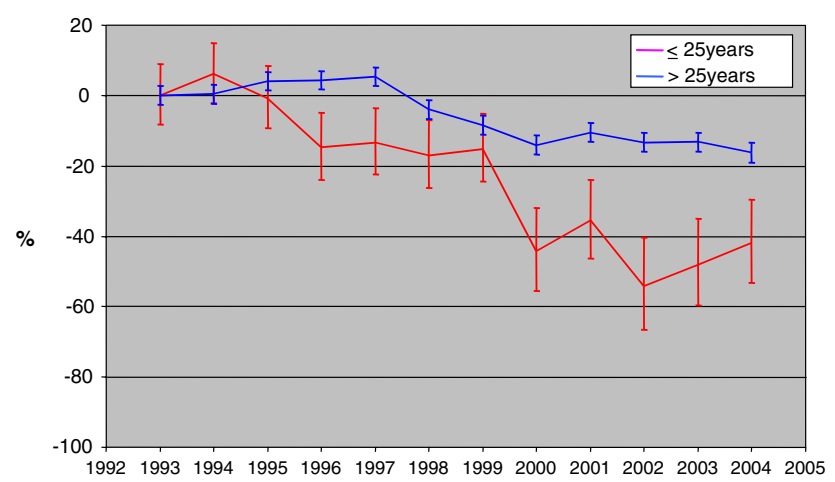

Fig. 2 Percentage change in the incidence of inpatient treatment for otosclerosis in relation to 1993. Patients over 25 years old (blue, $\mathrm{n}=60,765$ ) were defined as mainly unvaccinated, and those up to and including 25 years old (red, $n=3,347$ ) as vaccinated. In the unvaccinated patients, the incidence decreases by $16 \%$, and by $42 \%$ in vaccinated patients

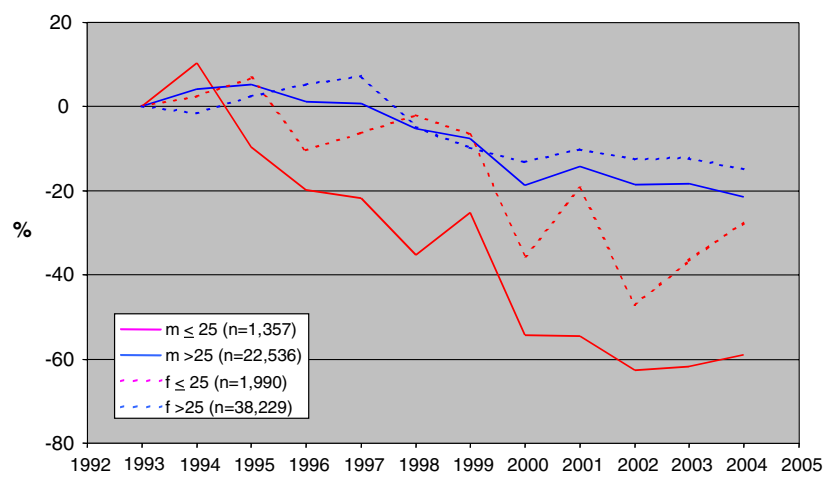

Fig. 3 Percentage change in the incidence of inpatient treatment for otosclerosis in relation to 1993, data expressed separately for men and women. In the vaccinated women (broken line, red), the incidence decreases by $27 \%$, and in the unvaccinated women (broken line, blue) by $15 \%$. Vaccinated men (solid line, red) show a decrease of the incidence by $59 \%$, as compared to $22 \%$ in the unvaccinated men (solid line, blue)

temporal bone of mainly white human beings. For this reason, criteria such as those stipulated as alternatives by B. Hill must have to be used to document the causal role of measles viruses in the etiology of otosclerosis [39].

Consistency of findings: various research groups arrive at the same immunohistochemical and molecular biological results at various times at different locations. As far as we know, there have been no further investigations apart from the present study on the epidemiological examination of the correlation between measles vaccination and otosclerosis.

Strength of correlation: up to now, proteins and RNA of measles viruses have only been demonstrated in otosclerotic bone material from patients with hearing loss due to otosclerosis. In non-otosclerotic bone material of the same patients or in bone material of patients with other ear diseases (e.g., otitis media), none of the investigators succeeded in demonstrating proteins or RNA from measles viruses.

Temporal relationship: after introduction of measles vaccination in 1974, there has been a remarkable decline in the incidence of otosclerosis in the vaccinated age groups (present study). A similar effect cannot be seen in otitis media patients.

Our epidemiological investigations on the change in the incidence of otosclerosis treated in hospital have shown that the incidence decreases to a significantly greater extent in the vaccinated age group than in the unvaccinated age group. We conclude from this that measles vaccination leads to a decrease of otosclerosis. It is difficult to identify other reasons, which might explain why younger patients continuously less frequently came for operation after 1993. Hearing aids were always an alternative to operations, but it is improbable that precisely the young patients under 25 years old should decide against an operation in favor of a hearing aid. For otosclerosis, there is no pharmacotherapeutic alternative to surgery. We did not find any indication that the notification practices in respect of young otosclerosis patients receiving inpatient treatment had changed in the course of the investigation period. The change of ICD-9 to ICD-10 in 1999 cannot explain the different decreases of incidence in the vaccinated and unvaccinated otosclerosis patients.

The smaller but clear decrease in the incidence of treatments for otosclerosis in hospital in the unvaccinated patients cannot be explained by a "herd immunity" induced by the measles vaccination. Otosclerosis is a persistent measles virus infection in which the infection must have taken place many years before the occurrence of clinical symptoms. Consequently, most of the unvaccinated patients had already been infected before the introduction of measles vaccination and hence could not profit from the "herd immunity" deriving from the vaccination.

Otitis media is a condition caused by a bacterial infection, which cannot be affected by measles vaccination. It must hence be assumed that the very similar decreases in incidence in unvaccinated otosclerosis patients and otitis media cases who have been vaccinated or not vaccinated are not disease-specific, and constitute a secular trend. In principle, a secular trend may be due to factors such as changes in health policy, strategy of treatment, notification practice or preventive health measures. The possible causes must be analyzed in a future investigation.

If the incidence of otosclerosis in the vaccinated population has declined significantly due to active immunization against measles viruses, the measles virus must play a causal role in the etiology of the 
Table 2 Frequency and incidence of inpatient treatments for otits media in Germany from 1993-2004

\begin{tabular}{|c|c|c|c|c|c|c|c|c|c|c|c|c|c|c|}
\hline & 1993 & 1994 & 1995 & 1996 & 1997 & 1998 & 1999 & 2000 & 2001 & 2002 & 2003 & 2004 & & \\
\hline $\begin{array}{l}\text { Frequency } \\
\text { Women }\end{array}$ & & & & & & & & & & & & & Total & \\
\hline Vaccinated & 5,134 & 5,562 & 5,892 & 5,947 & 6,239 & 6,526 & 5,824 & 5,396 & 4,985 & 5,075 & 5,021 & 4,375 & 65,976 & \\
\hline Unvaccinated & 6,747 & 7,769 & 9,004 & 9,248 & 9,523 & 9,403 & 8,950 & 7,656 & 7,164 & 7,277 & 6,828 & 6,116 & 95,685 & \\
\hline Men & & & & & & & & & & & & & & \\
\hline Vaccinated & 6,917 & 7,485 & 7,919 & 7,711 & 7,901 & 8,323 & 7,380 & 6,787 & 6,234 & 6,437 & 6,344 & 5,450 & 84,888 & \\
\hline Unvaccinated & 7,129 & 8,233 & 9,102 & 9,496 & 9,723 & 9,694 & 9,233 & 7,450 & 6,998 & 6,979 & 6,344 & 5,836 & 96,217 & \\
\hline $\begin{array}{l}\text { Total } \\
\text { Vaccinated } \\
\text { Unvaccinated }\end{array}$ & $\begin{array}{l}12,051 \\
13,876\end{array}$ & $\begin{array}{l}13,047 \\
16,002\end{array}$ & $\begin{array}{l}13,811 \\
18,106\end{array}$ & $\begin{array}{l}13,658 \\
18,744\end{array}$ & $\begin{array}{l}14,140 \\
19,246\end{array}$ & $\begin{array}{l}14,849 \\
19,097\end{array}$ & $\begin{array}{l}13,204 \\
18,183\end{array}$ & $\begin{array}{l}12,183 \\
15,106\end{array}$ & $\begin{array}{l}11,219 \\
14,162\end{array}$ & $\begin{array}{l}11,512 \\
14,256\end{array}$ & $\begin{array}{l}11,365 \\
13,172\end{array}$ & $\begin{array}{l}9,825 \\
11,952\end{array}$ & $\begin{array}{l}150,864 \\
191,902\end{array}$ & \\
\hline Incidence per 1 & 100,000 & & & & & & & & & & & & Average & Decrease (\%) \\
\hline $\begin{array}{l}\text { Women } \\
\text { Vaccinated } \\
\text { Unvaccinated }\end{array}$ & $\begin{array}{l}46.07 \\
22.00\end{array}$ & $\begin{array}{l}50.59 \\
25.14\end{array}$ & $\begin{array}{l}54.05 \\
28.97\end{array}$ & $\begin{array}{l}54.93 \\
30.33\end{array}$ & $\begin{array}{l}56.92 \\
30.83\end{array}$ & $\begin{array}{l}58.81 \\
30.05\end{array}$ & $\begin{array}{l}54.18 \\
28.57\end{array}$ & $\begin{array}{l}50.21 \\
24.42\end{array}$ & $\begin{array}{l}48.29 \\
23.80\end{array}$ & $\begin{array}{l}46.98 \\
23.05\end{array}$ & $\begin{array}{l}46.79 \\
21.65\end{array}$ & $\begin{array}{l}41.47 \\
19.36\end{array}$ & $\begin{array}{l}50.8 \\
25.7\end{array}$ & $\begin{array}{l}10 \\
12\end{array}$ \\
\hline $\begin{array}{l}\text { Men } \\
\text { Vaccinated } \\
\text { Unvaccinated }\end{array}$ & $\begin{array}{l}58.72 \\
25.70\end{array}$ & $\begin{array}{l}64.53 \\
29.34\end{array}$ & $\begin{array}{l}68.78 \\
32.13\end{array}$ & $\begin{array}{l}67.59 \\
33.26\end{array}$ & $\begin{array}{l}69.64 \\
33.97\end{array}$ & $\begin{array}{l}73.76 \\
33.79\end{array}$ & $\begin{array}{l}65.27 \\
32.08\end{array}$ & $\begin{array}{l}60.14 \\
25.80\end{array}$ & $\begin{array}{l}57.47 \\
25.19\end{array}$ & $\begin{array}{l}57.32 \\
23.97\end{array}$ & $\begin{array}{l}56.91 \\
21.72\end{array}$ & $\begin{array}{l}49.31 \\
19.92\end{array}$ & $\begin{array}{l}62.5 \\
28.0\end{array}$ & $\begin{array}{l}16 \\
23\end{array}$ \\
\hline $\begin{array}{l}\text { Total } \\
\text { Vaccinated } \\
\text { Unvaccinated }\end{array}$ & $\begin{array}{l}52.57 \\
23.75\end{array}$ & $\begin{array}{l}57.75 \\
27.14\end{array}$ & $\begin{array}{l}61.61 \\
30.47\end{array}$ & $\begin{array}{l}61.43 \\
31.75\end{array}$ & $\begin{array}{l}63.39 \\
32.34\end{array}$ & $\begin{array}{l}66.35 \\
31.84\end{array}$ & $\begin{array}{l}59.86 \\
30.25\end{array}$ & $\begin{array}{l}55.29 \\
25.08\end{array}$ & $\begin{array}{l}52.99 \\
24.47\end{array}$ & $\begin{array}{l}52.25 \\
23.49\end{array}$ & $\begin{array}{l}51.94 \\
21.68\end{array}$ & $\begin{array}{l}45.48 \\
19.63\end{array}$ & $\begin{array}{l}56.8 \\
26.8\end{array}$ & $\begin{array}{l}14 \\
17\end{array}$ \\
\hline
\end{tabular}

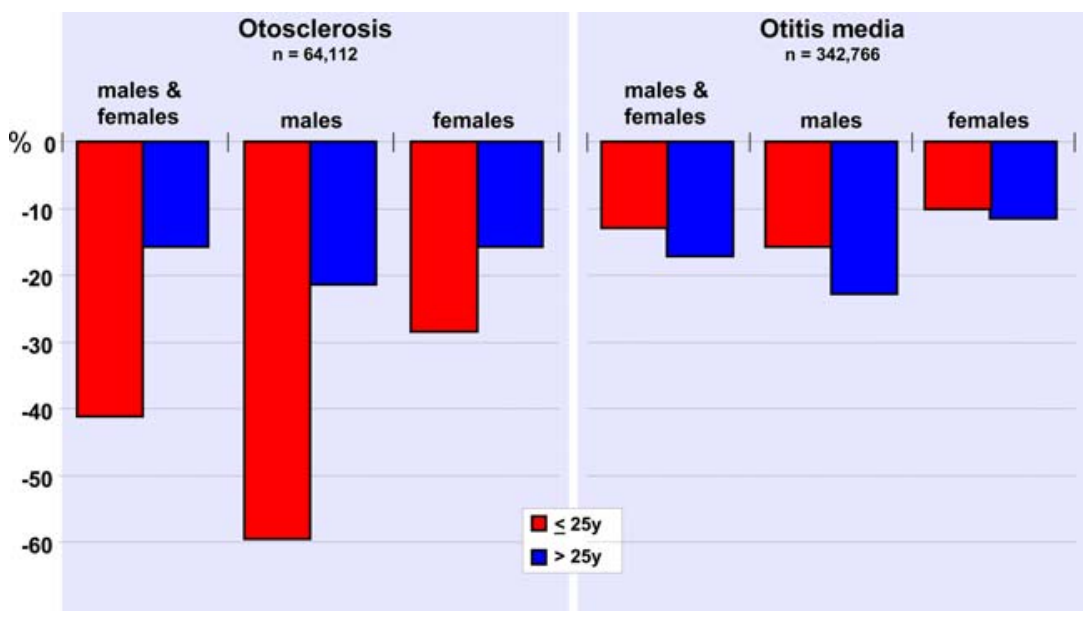

Fig. 4 Percentage change in the incidence of inpatient treatments for otosclerosis and otitis media between 1993 and 2004. In comparison of the vaccinated patients (red, up to and including 25 years old) with those defined as unvaccinated (blue, over 25 years old), a significant decrease of the incidence in the vacci-

disease. Since otosclerosis has a familial occurrence in up to $70 \%$ of cases, it is possible, that the measles virus binds to genetically (immunologically) preformed topographical regions of the temporal bone (e.g., anterior part of the oval window, promontory, stapes footplate, round window) [7]. The concomitant occurrence of a genetically determined high susceptibility for attachment of measles viruses (specific receptors?) and exogenously infiltrating measles virus induces the process of otosclerotic inflammation. If the measles virus is stopped from penetrating into "loci minoris resisten- nated patients is shown in the group with otosclerosis both in the group as a whole and in consideration of men and women separately. In the otitis media group, the incidence decreased more in the unvaccinated (blue) than in the vaccinated (red) patients both in men and women separately and in the overall group

tiae" owing to immunization of the host (vaccination), the process of bone remodeling cannot be initiated and the hearing loss due to otosclerosis does not occur. The measles virus is hence causally responsible for the development of otosclerosis and adequate vaccination of the population might prevent the development of otoslerotic hearing loss [40].

The finding that women respond to measles vaccination significantly less favorably than men $(27 \%$ as compared to $59 \%$ ) with regard to the clinical incidence of otosclerosis is difficult to interpret. It is known that 
women develop clinical otosclerosis more often than men (1.68:1, present study; 1.87:1, Switzerland; 2:1 according to the literature) [12]. A WHO study reports that throughout the world women die of the complications of a measles infection more frequently than men (1.42:1) [41]. Moreover, in West Africa the complications of measles vaccination occur more frequently in girls than in boys (1.93:1) [42]. The most plausible hypothesis to explain this is a genetically determined gender difference in the immune response to measles virus infection [43], an unique infectiological phenomenon.

\section{Conclusion}

Between 1993 and 2004 the incidence of hospital treatments for otosclerosis declined to a significantly greater extent in the vaccinated patient group than in the unvaccinated. The decrease is much greater in males than in females. A comparable effect cannot be seen in patients with otitis media. These results give support that the measles viruses are playing a causal role in the development of otosclerosis. The different response of the male and female gender may be due to a different reactivity of the female immune system to measles viruses.

\section{References}

1. Schuknecht HF (1993) Otosclerosis. In: Lea, Febiger A (eds) Pathology of the ear. 2nd edn. Waverly Company, Philadelphia-Baltimore-Hongkong-London-Munich-Sydney-Tokyo, pp 365-379

2. Roland PS, Meyerhoff WL (1998) Otosclerosis. In: Bailey BJ, Calhoun KH (eds) Head and neck surgery-otolaryngology, vol 141, 2nd edn. Lippincott-Raven, Philadelphia-New York, USA, pp 2083-2096

3. Guild SR (1944) Histologic otosclerosis. Ann Otol Rhinol Laryngol 53:246-266

4. Guild SR (1950) Incidence, location and extent of otosclerotic lesions. Am Arch Otolaryngol 52:848-852

5. Altmann F, Glasgold A, Macduff JP (1967) The incidence of otosclerosis as related to race and sex. Ann Otol Rhinol Laryngol 76:377-392

6. Friedmann J, Arnold W (1993) Otosclerosis. In: Friedmann J, Arnold W (eds) Pathology of the ear, 2nd edn. Churchill Livingstone, Edinburgh, England, pp 369-401

7. Gordon MA (1989) The genetics of otosclerosis: a review. Am J Otol 10:426-438

8. Morrison AW (1967) Genetic factors in otosclerosis. Ann R Coll Surg Eng 41:202-237

9. Van Den Bogaert K, Govaerts PJ, Schatteman J, Brown MR, Caethoven G, Offeciers FE, Somers T, Declau F, Coucke P, Van de Heyning P, Smith RJ, Van Camp G (2001) A second gene for otosclerosis, OTSC2 maps to chromosome 7q 34-36. Am J Hum Genet 68:495-500

10. Brownstein Z, Goldfarb A, Levi H, Frydaman M, Avraham KB (2006) Chromosomal mapping and phenotypic charac- terisation of hereditary otosclerosis linked to the OTSC4 locus. Arch Otolaryngol Head Neck Surg 132:416-424

11. Pearson RD, Kurland LT, Cody DTR (1974) Incidence of diagnosed clinical otosclerosis. Arch Otolaryngol 99:288-291

12. Vartiainen E (1999) Sex differences in patients with hearing impairments caused by otosclerosis. Eur Arch Otorhinolaryngol 256:431-433

13. Vrabec JT, Coker NJ (2004) Stapes surgery in the United States. Otol Neurotol 25:465-469

14. Mair JW (1989) Occasional stapes surgery-a Norwegian experience. J Laryngol Otol 103:259-262

15. Niedermeyer HP, Arnold W, Schwub D, Busch R, Wiest I, Sedlmeier R (2001) Shift of the distribution of age in patients with otosclerosis. Acta Otolaryngol 121:197-199

16. Arnold W, Friedmann JH (1988) Otosclerosis—an inflammatory disease of the otic capsule of viral aetiology? J Laryngol Otol 102:865-871

17. Schrader M, Poppendiek J, Weber B (1990) Immunohistologic findings in otosclerosis. Ann Otol Rhinol Laryngol 99:349352

18. McKenna MJ, Mills BG (2001) Immunohistochemical evidence of measles virus antigens in active otosclerosis. Otol Neurotol 22:249-257

19. Arnold W, Altermatt HJ, Kraft R, Pfaltz CR (1989) Die Otosklerose, eine durch Paramyxoviren unterhaltene Entzündungsreakton. HNO Springer 37:236-241

20. Niedermeyer HP, Arnold W, Neubert WJ, Höfler H (1994) Evidence of measles virus RNA in otosclerotic tissue. ORL J Otorhinolaryngol Relat Spec 56:130-132

21. McKenna MJ, Kristiansen AG, Haines J (1996) Polymerase chain reaction amplification of a measles virus sequence from human temporal bone sections with active otosclerosis. Am J Otol 7:827-830

22. Niedermeyer HP, Arnold W, Schuster M, Baumann C, Kramer J, Neubert WJ, Sedlmeier R (2001) Persistent measles virus infection and otosclerosis. Ann Otol Rhinol Laryngol 110:897-903

23. Niedermeyer HP, Arnold W, Neubert WJ, Sedlmeier R (2000) Persistent measles virus infection as a possible cause of otosclerosis: state of the art. Ear Nose Throat J 79:552554

24. Enders G (1987) Stand der Masern-, Mumps-und Rötelnschutzimpfung in der Bundesrepublik. Öffentliches Gesundheitswes 49:418-425

25. Olbing H (1985) Möglichkeiten zur Verbesserung der Durchimpfungsquoten. Deutsch Aerztebl 82:2555-2558

26. Stickl H (1983) Zur Lage der Masernimpfung in der Bundesrepublik Deutschland. Monatsschr Kinderheilkd 131:609-610

27. Scholz D (1989) Zur Masern-und Mumpsimpfung. Durchimpfungsgrad, Erkrankungshäufigkeit und "Impfdurchbrüche" bei Schulanfängern. Sozialpaediatrie Prax Klin 11:390-397

28. Fescharek R, Quast U, Maass G, Merkle W, Schwarz S (1990) Measles-mumps vaccination in the FRG: an empirical analysis after 14 years of use. I. Efficacy and analysis of vaccine failures. Vaccine 8:333-336

29. Enders G (1987) Masern, Mumps, Roeteln. In: Impfen nützt-Impfen schützt. Bundesvereinigung für Gesundheitserziehung, Bonn pp 65-77

30. Gerike E (1994) Impfung gegen Masern, Mumps und Roeteln. Paediatrie Grenzgeb 32:235-242

31. Hornetz KJ, Klein R (1995) Bevölkerungsbezogene Untersuchungen zum Durchimpfungsgrad von Einschulkindern im Saarland. Sozialpaediatrie Kinderärztliche Prax 17:350-352

32. Gerike E, Tischer A (1999) Masernimpfung in Deutschland. Immunol Impfen 2:110-120 
33. Gerike E, Tischer A (2000) Masernimpfung in Deutschland. Das Ziel ist die Elimination der Masern in Europa. Monatsschr Kinderheilkund 148:623-633

34. Tischer A, Siedler A, Rasch G (2001) Surveillance of measles in Germany. Gesundheitswesen 63:703-709

35. Statistical year books (1993-2004) Federal statistical office, Wiesbaden, Germany

36. Clopper C, Pearson S (1934) The use of confidential or fiducial limits illustrated in the case of binomial. Biometrika 26:404-413

37. Karosi T, Konya J, Petko M, Sziklai I (2005) Histologic otosclerosis is associated with the presence of measles virus in the stapes footplate. Otol Neurotol 26:1128-1133

38. Karosi T, Konya J, Petko M, Szabo LZ, Pytel J, Jori J, Sziklai I (2006) Antimeasles immunoglobulin g for serologic diagnosis of otosclerotic hearing loss. Laryngoscope 116:488-493
39. Hill B (1965) Environment und disease: association or Causation? Proc R Soc Med 58:295-300

40. Shea JJ Jr (1998) A personal history of stapedectomy. Am J Otol 19:S2-S12

41. Garenne M (1994) Sex differences in measles mortality: a world review. Int J Epidemiol 23:632-642

42. Aaby P, Jensen H, Samb B, Cisse B, Sodemann M, Jakobsen M, Poulsen A, Rodrigues A, Lisse IM, Simondon F, Whittle H (2003) Differences in female-male mortality after high-titre measles vaccine and association with subsequent vaccination with diphtheria-tetanus-pertussis and inactivated polio virus: reanalysis of West-African studies. Lancet 361:2183-2188

43. Green MS, Shoat T, Lerman Y, Cohen D, Slepon R, Duvdevani P, Varsano N, Dagan R, Mendelson E (1994) Sex differences in the humoral antibody response to live measles vaccine in young adults. Int J Epidermiol 23:1078-1081 